\title{
Thermomechanical Texturing by Instant Controlled Pressure-Drop DIC or How to Dramatically Intensify both Polyphenol Extraction and Antioxidant Activity of Algerian Myrtle Leaves
}

Baya Berka $^{1,2}$, Colette Besombes ${ }^{1}$, Aicha Hassani ${ }^{2}$ and Karim Allaf ${ }^{1, *}$ (1)

${ }^{1}$ La Rochelle University, Laboratory of Engineering Science for Environment LaSIE - UMR-CNRS 7356; avenue Michel Crepeau 17042 La Rochelle cedex 01, France

${ }^{2}$ Ecole Normale Supérieure de Kouba, B.P.92, Vieux-Kouba, 16500 Alger, Algeria

\section{Abstract}

Properly stirred solvent extraction has normally mass transfer diffusion as the limiting phenomenon. The texturing by instant-controlled pressure drop DIC can usually intensify the process. In the case of myrtle leaves, DIC operating parameters of dry saturated steam pressure, processing-time, and number of cycles were studied. The instant cooling by dropping pressure towards a vacuum of $5 \mathrm{kPa}$, and optimized DIC-texturing implied 140\%,250\%, and 228\% higher yields of flavonol, total flavonoid, and total phenol, respectively, in shorter time of 14 versus $110 \mathrm{~min}$. The antioxidant activity reached up to 2.8 higher than untextured leaves and 62 higher than BHT.

\section{Publication History:}

Received: October 14, 2019

Accepted: December 29, 2019

Published: December 31, 2019

\section{Keywords:}

Myrtus communis L., Solvent extraction, Instant controlled pressure drop DIC, Flavonol aglycones, Polyphenols, Flavonoids, Extraction kinetics, Antioxidant activity, Food composition, Food analysis, HPLC spectrophotometry analysis

\section{Introduction}

Myrtus communis $L$. is well known and appreciated since ancient times, both for use in religious cults as a culinary, aromatic, cosmetic and health product. This has made it familiar through the many legends that have circulated for its interest and reputation.

It is mainly spread all around the Mediterranean. Its presence is also indicated in many southern European countries, the Middle East and North Western Himalaya [1]. It is also present in other regions such as New Zealand, South America, Russia and Australia [1] Generally, it grows spontaneously in many climates and even in very poor siliceous or calcareous soils. This is an evergreen shrub and very aromatic leaves. When in bloom, it gives off a sweet and subtle flavor It is often associated with oak, mastic and Aleppo-pine forests. It is usually found at an altitude not exceeding $800 \mathrm{~m}$. In Algeria, the tree commonly called "el-Rayhan" or "el-halmouche" develops in the tell on the hillsides and coastal regions.

Beyond its richness and diversity of volatile compounds that constitute its familiar essential oils, myrtle also contains heavy compounds such as minerals, vitamins $\mathrm{A}$ and $\mathrm{B}$, flavonoids, coumarins, phenolic acids, myrtucommulone (MC), etc. Semimyrtucommulone (S-MC) is present mainly in the leaves and alkaloids in the roots. Their content, location and distribution largely depend on the organ involved but also the region. This wealth of various compounds is responsible for its biological activities, which tribute it with many pharmacological properties. It has been considered for hypoglycemic, analgesic, antiseptic, anti-inflammatory, antimicrobial and antioxidant uses [1]. Many studies focused on its therapeutic properties, chemotherapy, antidepressant, relaxing [2], and cardiovascular [2]. Many research studies have involved in vitro biochemical assays or animal pharmacology studies. However, more trials in humans are required to establish with absolute certainty the actual clinical efficacy of myrtle. Leaves and flowers of murtle are very popular in perfumery and in some cosmetics and pharmaceutical formulations [3]. Considered astringent, they also are very popular in tanning and dyeing. Its blue-black berries are edible and get nutritious properties [4-5]. They are used to make very popular liquors in Corsica and Sardinia [6] and to enhance certain dishes [7].

Although myrtle flavonoids are very important, studies in this area are very limited, probably due to the use of hydrodistillation as a conventional method of essential oil extraction, which induces a large hydrothermal degradation of the residual material. The first study on myrtle polyphenols was undertaken [5]. However, as far as we know, most of the work on polyphenols had mainly related to myrtle berries [8], with rare studies on polyphenols in leaves and other organs $[9,10]$.

The development of flavonoids has gained new impetus because of their numerous biological activities, food industry interest instead of synthesized antioxidants, and pharmacological properties. During recent decades, intensive research has been conducted on the effects of flavonoids on health. Numerous epidemiological studies have shown that regular consumption of rich-in-flavonoid fruits and vegetables allowed human natural defense to strengthen and have a protective role against the damage caused by cholesterol in the blood vessels and reduce the risk of cardiovascular disease, cancer, degenerative which are often caused by free radicals [11]. Other studies have also "Corresponding Author: Prof. Karim Allaf, LaSIE - UMR-CNRS 7356, avenue Michel Crepeau 17042 La Rochelle cedex 01, France; Tel: +33685816912; E-mail: kallaf@univ-Ir.fr

Citation: Berka B, Besombes C, Hassani A, Allaf K (2019) Thermomechanical Texturing by Instant Controlled Pressure-Drop DIC or How to Dramatically Intensify both Polyphenol Extraction and Antioxidant Activity of Algerian Myrtle leaves. Int J Clin Nutr Diet 5: 148. doi: https://doi.org/10.15344/2456$8171 / 2019 / 148$

Copyright: (c) 2019 Berka et al. This is an open-access article distributed under the terms of the Creative Commons Attribution License, which permits unrestricted use, distribution, and reproduction in any medium, provided the original author and source are credited. 
Citation: Berka B, Besombes C, Hassani A, Allaf K (2019) Thermomechanical Texturing by Instant Controlled Pressure-Drop DIC or How to Dramatically Intensify both Polyphenol Extraction and Antioxidant Activity of Algerian Myrtle leaves. Int J Clin Nutr Diet 5: 148. doi: https://oi.org/10.15344/2456-8171/2019/148

Page 2 of 15

suggested that flavonoids can reduce intracellular replication of HSV (herpes simplex virus) and HIV (human immunodeficiency virus) [12-13]. Because of the well-known toxicity of chemical antioxidants, many authors have mentioned the interest safety of almost all natural flavonoids [14]. This event is an important additional advantage that further strengthens their interest.

In food industry, and more specifically in the lipid sector, as well as in cosmetics and pharmaceuticals, the antioxidant additives are usually used against oxidation and rancidity by limiting or delaying oxidative damage resulting from the formation of many free radicals and can preserve products. These synthetic antioxidants are phenolic compounds of petrochemical origin such as propyl gallate (PG), butylated hydroxytoluene (BHT), butylhydroxyanisole (BHA) or tertbutylhydroquinone (TBHQ). Easy to make and inexpensive, they have, in recent years, been the object of reluctance by the vast majority of consumers because of their possible toxicity[15], possibly causing serious maladies such as cancers, cardiovascular and degenerative diseases, etc. associated with aging [16].

This has triggered a growing interest in natural antioxidants and left food, cosmetic, and pharmaceutical industries on the lookout for new natural antioxidant molecules that can effectively and advantageously replace synthetic compounds [17].

Consequently, the development of relevant methods for manufacturing plant-based natural flavonoids is urgently needed. Their effects on health are thoroughly evident since the discovery of the French paradox (low mortality in the Mediterranean population despite a high consumption of red wine and a diet rich in saturated fats) [18]. Many plant species could be lucrative for preservation sectors.

The extraction of flavonoid glycosides often leads to complex mixtures whose analysis mostly requires many standards. Their possible linkage with monosaccharides would imply a very delicate stage of extraction. For these reasons, it is sometimes more relevant and appropriate to operate the extraction of aglycones than flavonoid glycosides.

Extraction of flavonoids is typically carried out using ethanol, methanol or methanol-water mixtures, acetonitrile-water, or sometimes simply water. It can be carried out by hot or cold solution, under acid or neutral conditions according to the required compounds (glycosides or aglycones). It is done by leaching, maceration, percolation or Soxhlet reflux. Various works in this field have shown that there is no universal method to satisfactorily extract simultaneously all phenolic compounds from the plant materials. Each method is closely related to the profile of the required phenolic compounds.

Since the conventional extraction techniques cannot meet all the specific economic and technical requirements to extract plantbased natural compounds, recent research works have been oriented towards new technologies able to be more economical, Eco-friendly and further beneficial.

Accelerated Solvent Extraction (ASE) is a high-pressure extraction method, which can be performed with conventional solvents, suitable supercritical fluids, or subcritical water. It greatly reduces both processing time [19], and solvent consumption [20]. However, despite its important benefits in terms of product quality and environment; its too high cost in both terms of unit installation and energy consumption makes it often inaccessible. It is usually limited to the high added-value products.

In recent decades, microwave used for the extraction of polyphenolic compounds, has resulted in faster kinetics and lower energy consumption [21]. More recently, Chemat and coll [22] developed an assisted gravity microwave hydrodiffusion (MGH). This method improved both extraction time and yields of onion polyphenols and confirmed its great potential.

The ultrasound US-assisted solvent extraction reduces the volume of solvent [23], and increases extract quality and yields depending on power, temperature and stirring, but independently on compound polarity [24]. This extraction method is inexpensive, simple and often effective for the extraction of polyphenols [21]. Allaf et al. [25] attempted to elucidate the complex phenomenon of US assisted extraction by introducing the concept of higher internal mass convection within the vacuoles of open-porous matrix, somewhere reinforced by intrinsic ultrasonic cavitation. Thanks to its simplicity, US can also be combined and reinforce other intensification ways.

Recently, one of the most interesting innovative operations able to reduce the drawbacks of both conventional and new extraction methods has concerned plant texturing by "Instant controlled pressure drop" DIC as a very important pretreatment of the material. This procedure systematically mentioned as improving extraction kinetics is extremely fast and therefore advantageous in terms of energy cost and significant yields. Many experimental and fundamental works have already certified the exceptional impact of technique. Its industrial application areas are extensive and covering a wide range of products including drying and decontamination [26], texturing [27], archaeological wood preservation, the direct extraction of plant volatile compounds[28] etc. DIC has also paid to increase extraction of non-volatile molecules such as flavonoids [29].

The main objective of this study was to extend the numerous possibilities of DIC in extraction field. It should represent a real challenge not as an alternative or substitute to traditional methods but as essential way to improve the robust and well-controlled methods, and develop and optimize this DIC-assisted extraction process in saving time and energy for better industrial returns. It is obvious that the achievement of these objectives must be optimized using the response surface methodology (RSM). DIC process performance should be part of an intensification strategy to be observed as increasing both extraction kinetics and yields of flavonol aglycones, total phenols, and total flavonoids, as well as improving antioxidant activity.

\section{Materiels and Method}

\section{Plant material}

The myrtle leaves were harvested in full fruiting period (midNovember), in Bainem forest, located in the Northwest suburbs of Algiers. This limestone floor site, located away from pollution, enjoys the mild temperatures and humidity of the coast. It has dense and varied vegetation, with multi woody species and small plants. Myrtle was identified by the head of the herbarium of the National Institute of Agronomy of Algiers (INA).The fresh leaves, initially containing $0.938 \pm 0.005 \mathrm{~g} \mathrm{H}_{2} \mathrm{O} / \mathrm{g} \mathrm{db}$ (dry basis), were sorted, separated and then dried in an airflow at $29 \pm 1^{\circ} \mathrm{C}$, with $2.5 \mathrm{~m} / \mathrm{s}$ and Relative Humidity of vapor pressure of $260 \mathrm{~Pa}$. 
Citation: Berka B, Besombes C, Hassani A, Allaf K (2019) Thermomechanical Texturing by Instant Controlled Pressure-Drop DIC or How to Dramatically Intensify both Polyphenol Extraction and Antioxidant Activity of Algerian Myrtle leaves. Int J Clin Nutr Diet 5: 148. doi: https://oi.org/10.15344/2456-8171/2019/148

Page 3 of 15

\section{Chemicals and reagents}

All commercial products and standards (flavonols aglycone and antioxidants) were HPLC-analytical grade. They were supplied from Sigma-Aldrich, Fluka Chemicals (St. Quentin Fallavier, France), Extra synthese (Genay, France), and Apin Chemicals Limited (UK). All solutions and analyzes were performed with HPLC-analytical grade methanol from Carlo Erba (Val de Reuil, France). Water was Milli-Q quality.

\section{General Experimental Protocole}

The extraction-treatment protocol is illustrated in Figure 1. In the present frame, solvent extraction is studied as a pretreatment of myrtle leaves just prior to the solvent extraction.

\section{Instant controlled pressure-drop DIC treatment}

\section{DIC equipment and treatment}

The apparatus (Figure 2) has been described in many studies [30].

Briefly, DIC unit consists of three main parts:

1) Adouble-jacket processing vessel; (2), A vacuum tank having a double-jacket able to be cooled by a stream of cold water mainly during the extraction of volatile compounds; (3) A interconnecting instantaneously opening valve.

\section{DIC treatment process}

The first stage of DIC texturing was to identify the level of adequate water content. After some preliminary tests, the gradual partial drying

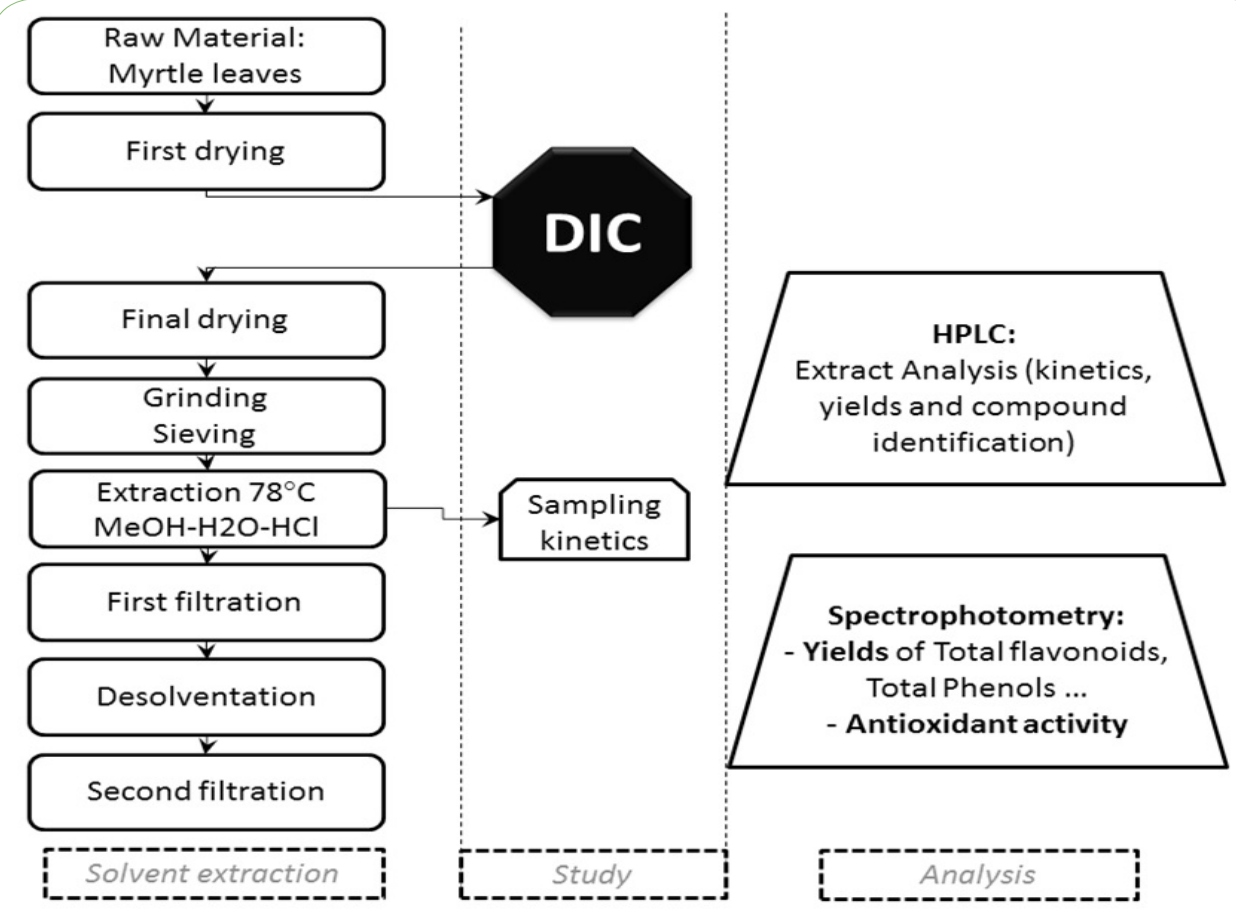

Figure 1: Treatment protocol and extraction-analysis.

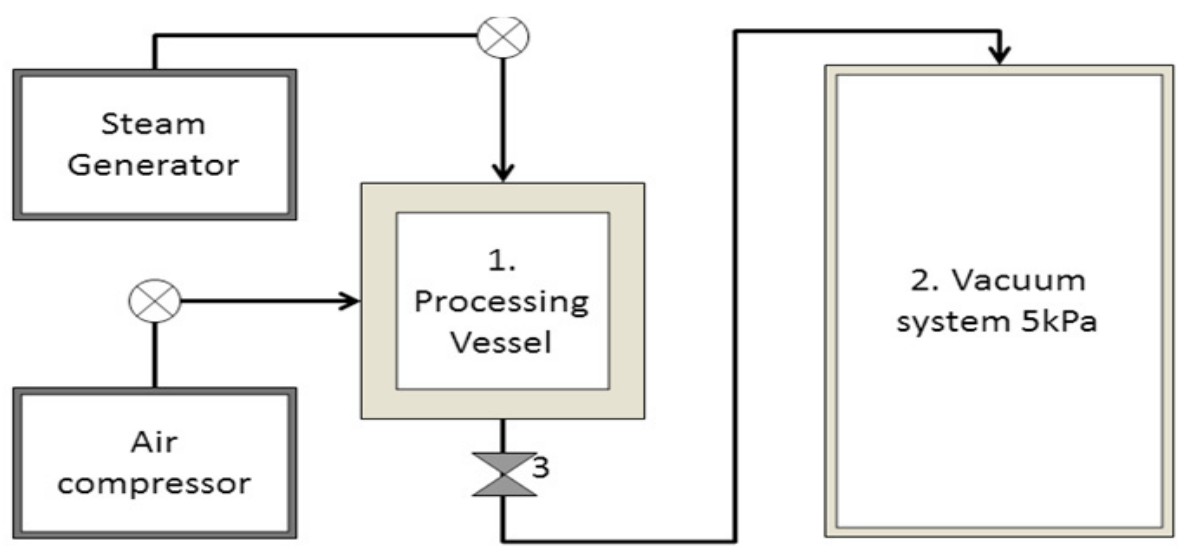

Figure 2: Scheme of a laboratory scale DIC reactor (ABCAR-DIC Process, La Rochelle, France): 1) A doublejacket processing vessel for high-temperature/high-pressure treatment; 2) A double-jacket vacuum tank with cooling liquid-stream; 3) An interconnecting instantaneously opening large-diameter valve. 
Citation: Berka B, Besombes C, Hassani A, Allaf K (2019) Thermomechanical Texturing by Instant Controlled Pressure-Drop DIC or How to Dramatically Intensify both Polyphenol Extraction and Antioxidant Activity of Algerian Myrtle leaves. Int J Clin Nutr Diet 5: 148. doi: https://oi.org/10.15344/2456-8171/2019/148

Page 4 of 15

was set for a final water content of $0.162 \pm 0.005 \mathrm{~g} \mathrm{H}_{2} \mathrm{O} / \mathrm{g} \mathrm{db}$. The leathery structure of myrtle leaves and the presence of a thick, waxy cuticle confer a certain resistance against water absorption after drying (impervious surface). Consequently, the irreversible structure of the leaves after drying followed by rehydration would not give similar conclusive results in terms of DIC texturing.

The DIC treatment protocol of the plant material occurs mainly in four distinct and successive steps. It starts by establishing a primary vacuum stage of about $5 \mathrm{kPa}$. This involves a better contact between the exchange surface and the next dry saturated steam flow thus reducing the "insulating barrier" of air. Thus, the heating stage is performed mainly by condensation of an adequate part of saturated steam at the raw material exchange surface with an equivalent convection coefficient of about $6000-60000 \mathrm{~W} \mathrm{~m}^{-2} \mathrm{~K}^{-1}$. The processing time is defined to assure homogeneity of both temperature and water content within the material. Just when the steam injection valve is closed, the large section instant opening valve is immediately opened. Instantaneously, the pressure drops towards a vacuum in ultrafast time of circa $0.02 / 0.06 \mathrm{~s}$, this results in a pressure drop rate of $\Delta \mathrm{P} / \Delta \mathrm{t}>1.5 \mathrm{MPa} \mathrm{s}^{-1}$. This brief and brutal action strictly linked with auto vaporization inevitably causes an almost instantaneous cooling towards about $31^{\circ} \mathrm{C}$ (thus stopping any thermal degradation), and a macroscopic texturing of the plant with a significant structural expansion of residual matrix.

In the present case of myrtle leaves, DIC treatment was performed with a number of cycles ranging from 1 to 6 . The last vacuum step of a cycle coincided with the initial vacuum phase of the next cycle.

Once processing was complete, the atmospheric pressure was restored. The textured myrtle leaves were collected and their humidity was measured. They were placed, possibly after dehydration, in sterile bags before being subjected to extraction, chromatography analysis, Scanning Electron Microscopy (SEM) micrograph, etc.

\section{Experimental strategy}

Many operating parameters can influence the performance of the extraction process. We can cite among others the nature of the solvent, $\mathrm{pH}$, temperature, solvent/charge ratio, particle size and shape, degree of agitation and possible defatting for the rich-in-lipid plants.

Consequently, several authors who studied the extraction of plant-based bioactive compounds used design of experiments. This allows using adequate software to determine the effects of the most representative factors and their interactions. This also overcomes the well-known difficulties normally encountered during a gradual one-by-one parameter study. A simple or multi-criteria optimization can be deduced. It is advisable to study the most influent operating parameters, to identify their impacts and optimize the treatment conditions.

For the present specific study, the first stage was to define the properly-said solvent extraction process. Afterwards, an adequate design of experimental for DIC-texturing treatment was performed. After some preliminary trials, three DIC operating factors whose influence seemed to be possibly significant were selected. Then, BoxBehnken Design of Experiments coupled to the Response Surface Method (RSM) allowed analyzing, studying and optimizing the DIC process performance. The yields, kinetics, and antioxidant activity were studied as response factors versus the DIC operating parameters, namely the dry saturated-steam pressure $\mathrm{P}$, the total processing-time $t$, and the number of cycles $n$, while the initial water content was maintained constant at $0.938 \pm 0.005 \mathrm{~g} \mathrm{H}_{2} \mathrm{O} / \mathrm{g} \mathrm{db}$ beforehand. This led to a 3-variable, 5-level design of experiments. 22 experiments were defined with 8 repetitions for the center point and were randomly performed. The response parameters were the yields of flavonoid aglycones, total phenols, and total flavonoids, and the factor of antioxidant activity. Analytical results were determined by RP-HPLC and by spectrophotometry.

\section{Assessments and analyses}

\section{Polyphenol extraction}

The extractions were carried out using $4 \mathrm{~g}$ of untextured and DIC-textured dry myrtle leaf powders (particle $\sim 0.5 \mathrm{~mm}$ ). They were conducted in hydroalcoholic acid medium $(75 \% \mathrm{MeOH}-$ $\mathrm{H}_{2} \mathrm{O} \mathrm{V} / \mathrm{V}$, acidified by $1.3 \mathrm{~mol} \mathrm{HCl}$ ). Extractions were carried out by refluxing $\left(78 \pm 1^{\circ} \mathrm{C}\right)$ and stirring at $500 \mathrm{rpm}$. Cooling water was kept at $5^{\circ} \mathrm{C}$ during the extractions. These conditions were defined after a preliminary study, which allowed the optimization of certain extraction parameters that were methanol/water ratio, the medium acidity and temperature.

The extraction kinetics were performed by regular sampling between the initial time until $240 \mathrm{~min}$. The extracts were filtered $(0.45$ $\mu \mathrm{m}$ PTFE membrane filter, Sartorius (Germany)) before the complete elimination of methanol. Afterward, the aqueous samples were filtered before being purified (removal of impurities and sugars) on SPE-type C18 columns (ODS- 5 Octadecyl, 18\% EC $500 \mathrm{mg} / 6 \mathrm{ml}$, Wahatman Inc. (USA)). Extracts collected from this sampling process of kinetic study were respectively placed in amber vials and bottles. They are stored in a freezer at $-20^{\circ} \mathrm{C}$, to be analyzed by HPLC and by spectrophotometry to measure the contents of total flavonoids and total phenols, and the antioxidant activity. The final solutions were also used to perform the corresponding assays. All spectrophotometric measurements were carried out according to their maximum absorbance with a UVVIS spectrophotometer model Helios Omega brand Thermo Fisher Scientific (Saint Herblain, France).

\section{Measurements of total phenols}

The phenol content of each sample was determined with the Folin-Ciocalteu reagent (FCR) method. A volume of $2.5 \mathrm{ml}$ of $10-$ time diluted FCR was added to $0.5 \mathrm{ml}$ of suitably diluted extract. After 2 minas standing time, $2 \mathrm{ml}$ of $20 \% \mathrm{Na}_{2} \mathrm{CO}_{3}$ were added to this mixture, which was stirred vigorously with a vortex, to be left at room temperature of $21^{\circ} \mathrm{C}$ for $90 \mathrm{~min}$. The extracts acquired a blue color with a maximum absorbance observed at $760 \mathrm{~nm}$ in the presence of a blank. The intensity of the color depends on the amount of phenols present in the plant extract. Dosages of the total phenols were made relative to a reference of standard compound Gallic Acid (GA). A calibration curve was performed using different concentrations thereof. The results were expressed as $\mathrm{mg}$ of gallic acid equivalent per gram of dry basis (mgGAE/gdb). All measurements were triplicated.

\section{Determination of total flavonoids}

In an alkaline medium, the flavonoids present in the extract reacted with the aluminum trichloride in the presence of sodium nitrite, giving a pink complex with a maximum absorbance recorded at 510 $\mathrm{nm}$. The measurements of total flavonoids were performed on the 
Citation: Berka B, Besombes C, Hassani A, Allaf K (2019) Thermomechanical Texturing by Instant Controlled Pressure-Drop DIC or How to Dramatically Intensify both Polyphenol Extraction and Antioxidant Activity of Algerian Myrtle leaves. Int J Clin Nutr Diet 5: 148. doi: https://oi.org/10.15344/2456-8171/2019/148

Page 5 of 15

extracts obtained from bothuntextured and DIC-textured myrtle leaves using a slightly modified version of Zhishen et al. [31] method.

In a flask of $5 \mathrm{ml}$, we consecutively introduced $0.5 \mathrm{ml}$ of diluted extract, $2.5 \mathrm{ml}$ of distilled water, and $0.15 \mathrm{ml}$ of $5 \%$ solution of $\mathrm{NaNO}_{2}$. After 5 min of waiting time at room temperature of $21^{\circ} \mathrm{C}$, we added a volume of $0.3 \mathrm{ml}$ of $10 \% \mathrm{AlCl}_{3}$, stand for further $6 \mathrm{~min}$ at room temperature, and, just after included $1 \mathrm{ml}$ of $1 \mathrm{M}-\mathrm{NaOH}$ and a volume of distilled water to achieve the total volume of the flask. The resulting mixture was stirred vigorously with a vortex. The absorbance is then measured at $510 \mathrm{~nm}$ in the presence of a blank. A calibration curve was performed using different catechin concentrations used as reference. Total flavonoids (TF) content in different extracts were evaluated from this curve. The results are expressed as $\mathrm{mg}$ catechin equivalent per gram of dry basis (mg CatE/gdb). All measurements were triplicated.

\section{Mesurements of flavonol aglycones by HPLC}

HPLC analyses of total flavonoid aglycones (TFA) were performed with a gas chromatograph Agilent Technologies brand Model 1100 (Massy, France). It is equipped with a quaternary pump, an autoinjector, a degasser, a column thermostat, an autosampler, and a diode-array detector (DAD) UV-VIS. The computer control system and data evaluation and processing were managed by a Chem Station software computer coupled to RP-HPLC column Phenomenex Luna C18 (2) of size $250 \mathrm{~mm}$ x $4.6 \mathrm{~mm}$ and a porosity of $5 \mu \mathrm{m}$.

The column temperature was maintained at $28^{\circ} \mathrm{C}$. The flow rate of the mobile phase was $0.5 \mathrm{ml} / \mathrm{min}$ and the maximum wavelength was set at $\lambda=370 \mathrm{~nm}$. The injection volume was $20 \mu l$.The elution of the compounds was carried out in gradient mode. The binary mobile phase (table 1) consists of purified water-methanol 70\% V/V slightly acidified by $0.05 \%$ TFA (solution $\mathrm{A}$ ) and pure methanol acidified with $0.05 \%$ TFA (solution B).

\begin{tabular}{|l|l|l|l|l|l|l|}
\hline $\begin{array}{l}\text { Time } \\
(\mathrm{min})\end{array}$ & 0 & 6 & 27 & 32 & 35 & 38 \\
\hline $\begin{array}{l}\% \text { solution } \\
\text { A }\end{array}$ & $\begin{array}{l}\text { Purified water-methanol 70\% V/V slightly acidified } \\
\text { by 0.05\% TFA }\end{array}$ \\
\hline $\begin{array}{l}\% \text { solution } \\
\text { B }\end{array}$ & 24 & 24 & 85 & 85 & 24 & 24 \\
\hline
\end{tabular}

Table 1: Elution gradient for the analysis of myrtle flavonol aglycones.

A myricetin (Myr) standard solution was prepared with a concentration range from 10 to $250 \mu \mathrm{g} / \mathrm{ml}$ from a stock solution of $2 \mathrm{mg} / \mathrm{ml}$. All solutions were analyzed under the same conditions as the extracts.

\section{Assessments of antioxidant activity}

In the presence of an antioxidant, reduction of the free radical DPPH is accompanied by a decrease in the coloration intensity or discoloration from yellow to violet. The redox reactions are monitored by spectrophotometry.

The antioxidant activity was evaluated by the method of trapping the free radical 2,2-Diphenyl-1-picrylhydrazyl (DPPH•) by polyphenols for all the extracts obtained from the untextured and differently DICtextured myrtle leaves.

The performance of this activity was expressed by $\mathrm{IC}_{50}$, which is the extract concentration required for $50 \%$ bleach free radical DPPH. The lower the $\mathrm{IC}_{50}$ value of a sample, the higher its antioxidant activity. The color change ratio was correlated to the antioxidant concentration. However, the correlation between it and the scavenging activity was not linear. This can be caused by some differences that induce errors [32].

Briefly, $3 \mathrm{ml}$ of $0.3 \mathrm{mM}$ DPPH $\bullet$ were added to $1 \mathrm{ml}$ of diluted myrtle extract. The reaction mixture was stirred vigorously and then left for 30 min waiting time at room temperature of $21^{\circ} \mathrm{C}$ in a dark place away from any light source. Subsequently, the maximum absorbance of the reaction mixture was measured at $516 \mathrm{~nm}$ wavelength against a blank consisting of a mixture of $1 \mathrm{ml}$ of the same extract and $3 \mathrm{ml}$ of methanol. Several dilutions were made until stabilization of the absorbance. The antioxidant activity of myrtle extracts was compared to three commercial antioxidants taken as references; $\mathrm{BHT}$, quercetin and gallic acid.

The different dilutions were obtained from the stock solutions of 200,100 , and $50 \mu \mathrm{g} / \mathrm{ml}$ for BHT, Quercetin, and Gallic Acid, respectively. These antioxidants were subjected to the same triplicated evaluation of the antioxidant capacity procedure.

\section{Results}

\section{Assessmentsof flavonol aglycones by RP-HPLC-DAD}

\section{Process design}

The dry saturated steam pressure of DIC treatment revealed the processing temperature level and the number of pressure-drops should reflect the auto vaporization effects. In most cases, these two operating parameters are very important whilst the treatment time can be less influential. The effects of these three parameters were quantified using the methodology of Design of Experiments DoE, by means of a software Statgraphics Plus version 5.1 [33]. This provides a polynomial equation combining each response (Y: dependent variable) to a second order of different operating parameters $x_{i}$ (independent variables). Presentation can also be revealed through response surfaces, Pareto chart, iso responses, etc. 5-level rotative centered composite map allows tracking the individual linear, interaction, and quadratic influences of these operating parameters for each response $\mathrm{Y}$ :

$$
Y=\beta_{0}+\sum_{i=1}^{n} \beta_{i} x_{i}+\sum_{i=1}^{n} \beta_{i i} x_{i}^{2}+\sum_{i=1}^{n-1} \sum_{\substack{i=1 \\ j \neq i}}^{n} \beta_{i j} x_{i} x_{j}+\varepsilon
$$

With $\beta_{0}, \beta_{i}, \beta_{i i}$, and $\beta_{i j}$ are the regression coefficients of the mathematical adopted model. They are determined from experimental results obtained in this case for different yields (total and individual flavonol aglycones, total flavonoids and total phenols) and antioxidant activity of the extracts. $\mathrm{n}$ is the number of independent operating parameters used to realize the design of experiments; in the present case: $\mathrm{n}=3$. $\varepsilon$ results from experimental error and raw material possible variability, etc. $\mathrm{Y}$ is the targeted response factor; in this study it concerned different yields of total and individual flavonol aglycones, total flavonoids, and total phenols, and finally antioxidant activity $\left(\mathrm{IC}_{50}\right)$ of various extracts. Levels of each of the operating parameters involved in the development of experimental design associated with DIC treatment are summarized in Table 2. 
Citation: Berka B, Besombes C, Hassani A, Allaf K (2019) Thermomechanical Texturing by Instant Controlled Pressure-Drop DIC or How to Dramatically Intensify both Polyphenol Extraction and Antioxidant Activity of Algerian Myrtle leaves. Int J Clin Nutr Diet 5: 148. doi: https://oi.org/10.15344/2456-8171/2019/148

Page 6 of 15

HPLC analysis of the aglycone flavonols contained in untextured and DIC-textured leaves of Myrtus communis $L$.

\section{Influence of DIC treatment on the extraction of flavonol aglycones myrtle}

Myrtle extracts were first subjected to spectrophotometric scanning. The maximum absorption was observed for a wavelength of around $370 \mathrm{~nm}$.

Extraction kinetic was studied during $240 \mathrm{~min}$ for untextured and differently DIC-textured leaves. This allowed optimizing the extraction time at $110 \mathrm{~min}$. Analysis of the simultaneous effects of various parameters of DIC treatment on the extraction yield from the leaves of the myrtle is reported in Figure 3.

The performance of the proposed model is evaluated with the value of $\mathrm{R}^{2}$. In the case of TFA extraction analyzed by HPLC, $\mathrm{R}^{2}$ was equal to $91 \%$, and the adjusted value was $84 \%$. Consequently, these values indicate a significant correlation between the experimental results and the empirical mathematical model.

The influence of DIC processing parameters and their mutual interactions on the total amount of myrtle leaf aglycone flavonols analyzed by HPLC is given by equation 2, which considers effects of linear, quadratic and interaction.

$$
\begin{aligned}
\text { Yield }_{T F A} & =33.51-36.28 P-0.06 t-6.58 C+49.93 P^{2}+0.06 P t \\
& -0.11 P C-4.10^{-5} t^{2}+0.01 t C+0.72 C^{2}
\end{aligned}
$$

Yield $_{\text {TFA }}$ represents the total amount of aglycone flavonols TFA extracted from myrtle leaves DIC-processed and analyzed by HPLC, where $\mathrm{P}$ is the pressure in $\mathrm{MPa}, \mathrm{t}$ the total heating time in seconds and $\mathrm{C}$ is the number of cycles.

Figure 3 shows that Yield ${ }_{\text {TFA }}$ mainly increased with saturated steam pressure and number of cycles, whilst treatment time influence was less pronounced that the first two parameters.

The total amount of aglycone flavonols (TFA) extracted after 110 min was 19.60 against $13.97 \mathrm{mgMyrE} / \mathrm{g}$ db for DIC textured (at 0.5 MPa, $180 \mathrm{~s}$ and 5 cycles) and untextured myrtle leaves, respectively. This value represents $40.30 \%$ increasing value for DIC textured leaves in comparison to that of the untreated raw material. In the case of DIC textured myrtle leaves, the major compound was identified as myricetin. HPLC analysis of the extracts obtained by $110-\mathrm{min}$ extraction from raw material and DIC-textured leaves are listed in Table 3.

\begin{tabular}{|l|l|l|l|}
\hline \multicolumn{3}{|c|}{ Independent variables } \\
\hline $\begin{array}{l}\text { Coded } \\
\text { values }\end{array}$ & $\begin{array}{c}|c| \\
\mathrm{X}_{1}=\mathrm{P} \\
\text { Saturated steam } \\
\text { pressure }(\mathrm{MPa})\end{array}$ & $\begin{array}{c}\mathrm{X}_{2}=\mathrm{t} \\
\text { Total thermal } \\
\text { treatment time }(\mathrm{s})\end{array}$ & $\begin{array}{c}\mathrm{X}_{3}=\mathrm{C} \\
\text { Number of cycles } \\
/\end{array}$ \\
\hline$-a$ & 0.10 & 19 & 2 \\
\hline-1 & 0.2 & 60 & 3 \\
\hline 0 & 0.35 & 120 & 4 \\
\hline 1 & 0.5 & 180 & 5 \\
\hline$+a$ & 0.6 & 221 & 6 \\
\hline
\end{tabular}

Table 2: Level of operating parameters defined in the response area methodology (RSM) of DIC treatment of leaves of Myrtus communis L.

\section{Impact of DIC treatment on flavonol aglycone composition of Myrtus communis L.}

Analyses of extracts by RP-HPLC-DAD revealed six compounds of the family of flavonols. Two were clearly present in all DIC-textured samples; they were the myricetin, followed by myricetin 3-O-methyl. This last is a uncommon compound whosemethylation at position 3 decreases its polarity and increases its retention time compared with myricetin. Conversely, for the untextured myrtle leaves, the major compound was myricetin 3-O-methyl followed by myricetin. Quercetin and kaempferol were also present in different extracts at significantly lower amounts.
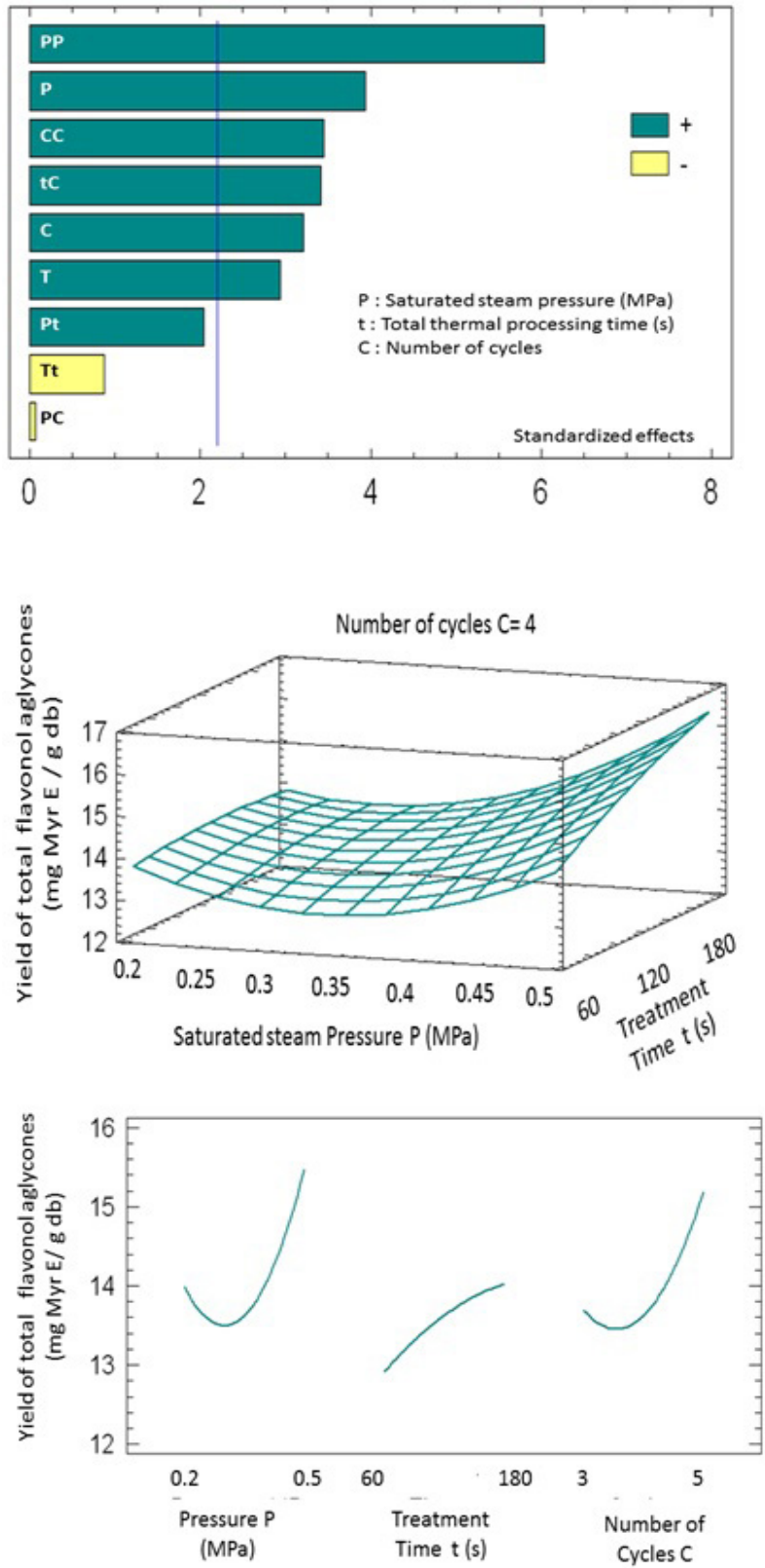

Figure 3: Effects of DIC treatment on the yield of total flavonol aglycones (TFA) of myrtle leaves: a) Pareto chart at confidence of $95 \%$ (p-value $<0.05)$; b) Response surface depending on steam pressure and treatment time at number of cycles 4 ; c) General trends. 
Citation: Berka B, Besombes C, Hassani A, Allaf K (2019) Thermomechanical Texturing by Instant Controlled Pressure-Drop DIC or How to Dramatically Intensify both Polyphenol Extraction and Antioxidant Activity of Algerian Myrtle leaves. Int J Clin Nutr Diet 5: 148. doi: https://oi.org/10.15344/2456-8171/2019/148

Page 7 of 15

Two other compounds (3 and 6) were present. They also were quantified at too low levels without being identified.
The identification of four aglycones contained in the extracts was made by comparing their retention times with those of standard

\begin{tabular}{|c|c|c|c|c|c|}
\hline Trial $N^{\circ}$ & $\mathrm{P}(\mathrm{MPa})$ & $t(s)$ & $\mathrm{C}$ & TFA (mg MyrE/gdb) & Extraction Ratio (\%) \\
\hline Raw Material (RM) & & & & $13.97 \pm 0.86$ & $100 \%$ \\
\hline CP 8 (DIC-CP) & 0.35 & 120 & 4 & $13.63 \pm 0.37$ & $98 \% \pm 3 \%$ \\
\hline $\mathrm{DIC1}$ & 0.2 & 180 & 5 & 16.57 & $119 \%$ \\
\hline DIC2 & 0.1 & 120 & 4 & 15.33 & $110 \%$ \\
\hline DIC3 & 0.35 & 19 & 4 & 13.13 & $94 \%$ \\
\hline DIC5 & 0.5 & 60 & 5 & 14.35 & $103 \%$ \\
\hline DIC7 & 0.2 & 180 & 3 & 13.85 & $99 \%$ \\
\hline DIC8 & 0.5 & 180 & 3 & 15.75 & $113 \%$ \\
\hline DIC10 & 0.35 & 120 & 2 & 14 & $100 \%$ \\
\hline DIC12 & 0.2 & 60 & 5 & 14.53 & $104 \%$ \\
\hline DIC13 & 0.2 & 60 & 3 & 13.99 & $100 \%$ \\
\hline DIC14 & 0.35 & 120 & 6 & 16.95 & $121 \%$ \\
\hline DIC16 & 0.6 & 120 & 4 & 17.9 & $128 \%$ \\
\hline DIC18 & 0.35 & 120 & 4 & 13.68 & $98 \%$ \\
\hline DIC19 & 0.5 & 180 & 5 & 19.6 & $140 \%$ \\
\hline DIC20 & 0.35 & 221 & 4 & 12.98 & $93 \%$ \\
\hline DIC22 & 0.5 & 60 & 3 & 15.07 & $108 \%$ \\
\hline
\end{tabular}

Table 3: Results of HPLC analyses of total flavonol aglycones (TFA) with untextured raw-material (RM) and DIC-textured myrtle leaves.

DIC conditions P: saturated steam pressure, t: thermal treatment time, C: number of cycles; $\mathrm{CP} 8$ (DIC-CP) Central Points at $\mathrm{P}=0.35$ $\mathrm{MPa} ; \mathrm{t}=120 \mathrm{~s} ; \mathrm{c}=4$.<smiles>O=c1c(O)c(-c2cc(O)c(O)c(O)c2)oc2cc(O)cc(O)c12</smiles>

$1=$ Myricetin<smiles>O=c1c(O)c(-c2ccc(O)c(O)c2)oc2cc(O)cc(O)c12</smiles>

\section{4 = Quercetin}<smiles>COc1c(-c2cc(O)c(O)c(O)c2)oc2cc(O)cc(O)c2c1=O</smiles>

$2=$ Myricetin 3-O-methyl<smiles>O=c1c(O)c(-c2ccc(O)cc2)oc2cc(O)cc(O)c12</smiles>

$5=$ Kaempferol

Figure 4: Structures of the four flavonoid aglycones identified by HPLC in myrtle leaf extracts. 
Citation: Berka B, Besombes C, Hassani A, Allaf K (2019) Thermomechanical Texturing by Instant Controlled Pressure-Drop DIC or How to Dramatically Intensify both Polyphenol Extraction and Antioxidant Activity of Algerian Myrtle leaves. Int J Clin Nutr Diet 5: 148. doi: https://oi.org/10.15344/2456-8171/2019/148

Page 8 of 15

commercial compounds of HPLC grade. The order of elution was done according to their polarity. Their structures are shown in Figure 4.
The chromatograms shown in Figure 5 show the inherent substantial changes in DIC textured materials compared with untreated myrtle leaves as a reference.

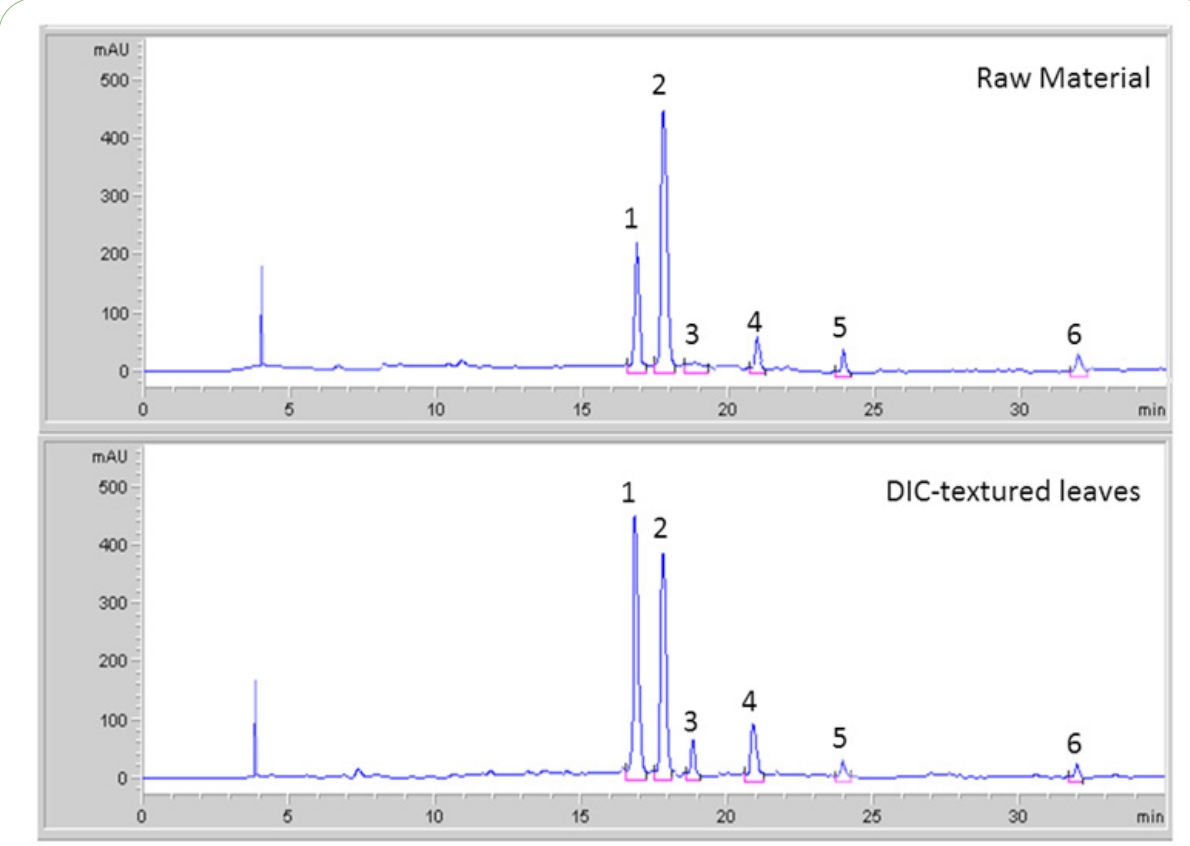

Figure 5: Chromatograms analyzes (HPLC) untreated (MP) and treated (MT). Flavonic extracts of myrtle (HPLC chromatogram flavonic compounds with retention time, peak $1=$ myricetin $(\operatorname{tr}=17.08 \mathrm{~min}$ ), peak $2=$ methyl-3-O-myricetin $(\operatorname{tr}=17.93 \mathrm{~min})$, peak $3=$ unknown flavonol $(\mathrm{Tr}=18.67)$, peak $4=$ quercetin $(\operatorname{tr}=21.03 \mathrm{~min})$, peak $5=$ kaempferol $(\operatorname{tr}=24.48 \mathrm{~min})$, and peak $6=$ unknown flavonol $(\operatorname{tr}=$ $32.79 \mathrm{~min})$.
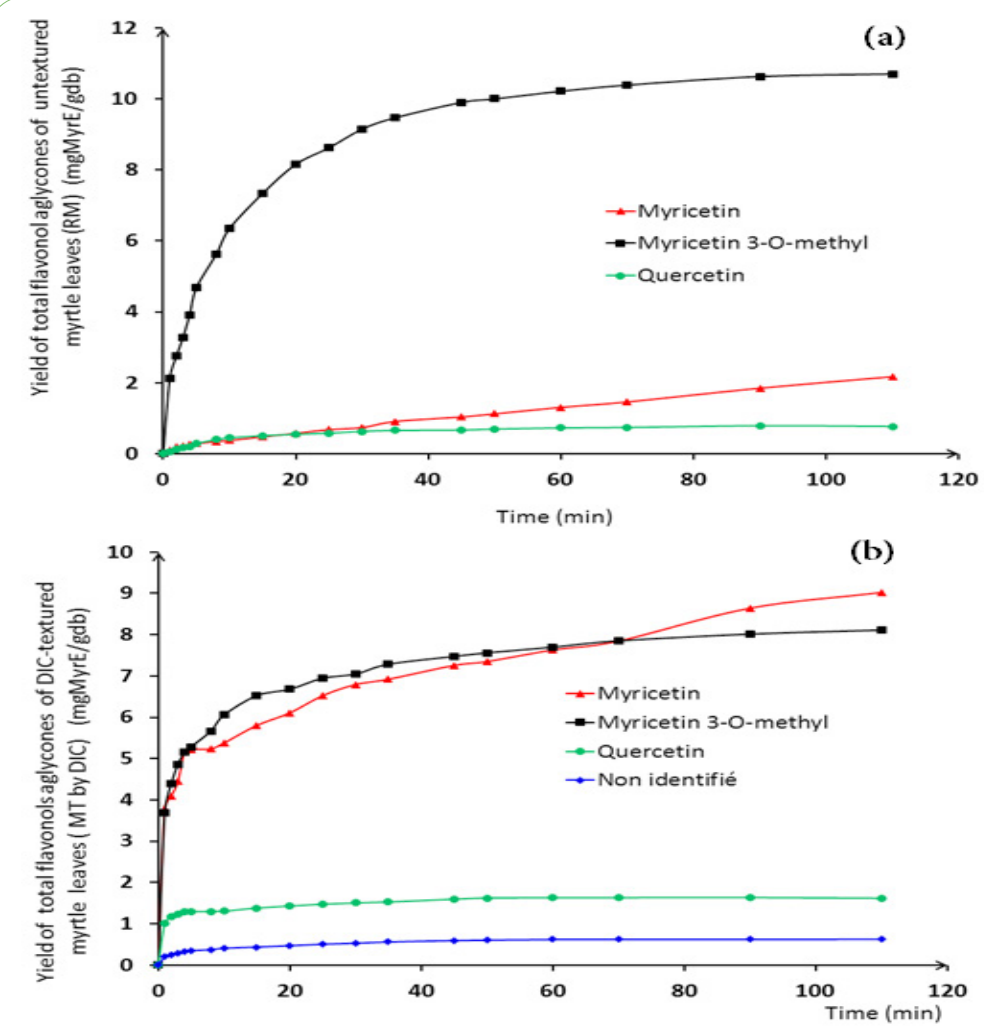

Figure 6: Extraction kinetics of the main compounds as yields versus time from a) untextured (RM), and b) DIC-textured (TM) myrtle leaves analyzed by HPLC. 
Citation: Berka B, Besombes C, Hassani A, Allaf K (2019) Thermomechanical Texturing by Instant Controlled Pressure-Drop DIC or How to Dramatically Intensify both Polyphenol Extraction and Antioxidant Activity of Algerian Myrtle leaves. Int J Clin Nutr Diet 5: 148. doi: https://oi.org/10.15344/2456-8171/2019/148

Page 9 of 15

High performance reverse phase liquid chromatography (HPLC) coupled to a UV-visible spectrophotometer detector diode array (RP-HPLC-DAD)/ elution gradient method has proven a great performance in the analysis of extracts obtained from untextured and DIC-textured myrtle leaves. Flavonol aglycones were unambiguously eluted to distinct well-separated retention time.

It is obvious that the flavonoid contents found in vegetable matrix (plants, fruits, vegetables, etc.) can considerably vary depending on year, location (soil type), environment growth conditions and climate change (sunshine, lack or excess of water, wind ...). The harvest season can also be a source of significant impact on the content. Thus, among the first studies on polyphenolic components extracted from the myrtle leaves, four flavonol glycosides, which were the glucosyl 3-quercetin, galactosyl 3-quercetin, galactosyl 3-myricetin, and rhamnosyl 3- myricetin. The continuation of this work [34] allowed isolating another flavonic compound having the characteristics of an acylated glycoside. The acid hydrolysis allowed releasing glucose; quercetin and gallic acid. Work dealing with myrtle leaves growing in Greece highlighted two myricetin and kaempferol aglycones. Further limited work [35-36] ensued, quantified, and identified by HPLCMS-ES myricetin-3-O-galactoside, myricetin-3-O-rhamnoside (myricitrin), which was the major component but by far followed by quercetin-3-O-galactoside (hyperoside) and quercetin-3-Orhamnoside (quercitrin). Among these compounds also were further derivatives of myricetin but they were not precisely identified. These same compounds were obtained from the berries of myrtle growing in Corsica; they revealed significant proportions of myricetin, quercetin, and kaempferol [37-38].

A recent study [39] reported that the myrtle growing in Egypt contained myricetin-3-O- $\beta$-glucopyranoside and myricetin-3-O- $\alpha$ rhamnopyranoside. Also, for the first time the heteroside 3-methoxy myricetin 7-O- $\alpha$-L-rhamnopyranoside in myrtle leaves growing in Egypt. The aglycone 3-methoxy myricetin obtained by acid hydrolysis was identified by NMR spectroscopy $\mathrm{C}^{13}$ and $\mathrm{H}^{1}$.

\section{Kinetics of extraction of flavonol aglycones from untextured and DIC-textured myrtle leaves}

Figure 6 shows the kinetics of extraction of various flavonol aglycone compounds from untextured and DIC-textured myrtle leaves treated at $0.5 \mathrm{MPa}$ steam pressure, $180 \mathrm{~s}$ heating time, and 5 cycles.

The extraction kinetic curves show that myricetin 3-O-methyl was the most important compound of myrtle leaves. The optimal conditions of DIC texturing preserved its yield however strictly escorted by an extensively much higher yield of Myricetin. This natural antioxidant flavonol found in many foods and vegetables has important biological activities. In addition to its antioxidant capacity, it is assigned an important role in protecting against some cancers. In particular [40] associated it with a lower rate of prostate cancer.

At the first stage, the aglycone myricetin 3-O-methyl had faster extraction. It almost reached a plateau after $60 \mathrm{~min}$. It is while myricetin requested more time to be extracted completely. This phenomenon should be correlated firstly with the location of flavonols and secondly the resistance to diffusion through the cell tissue of myrtle leaves. Indeed, some simple non-polar flavonoids, such as methyl derivative flavonoids, are often accumulated in the leaf surface exudates. This location may possibly explain the rapid extraction of nearly all of myricetin 3-O-methyl.

Table 4 shows the yields and the various changes in terms of improvement percentage that took place at 110-min extraction. For DIC textured myrtle leaves compared to untreated material as a reference, it was observed simultaneously a substantial $316 \%$ improvement of Myricetin and 24\% decrease of myricetin 3-O methyl.

For the other four compounds, which were weakly present in the case of untreated myrtle, DIC texturing implied an increase of $6200 \%$ in the compound 3, and $110 \%$ in Quercetin, and there was no significant change for the other compounds. The great functional quality of Quercitin [41] fortified even more the importance of DIC treatment.

Figure 7 shows that the maximum amount of flavonoids reached after 110 min of extraction for untreated leaves was obtained within 14 min of extraction in the case of DIC-textured myrtle leaves, which means almost eight times faster. This rapid increase in the extraction of TFA should be correlated with the brutal and instantaneous decompression to vacuum, which generated a significant change in the internal structure of the leaves. DIC alveolation result in a starting accessibility much higher than the conventional extraction without DIC texturing. Henceforth, this overcomes the resistance exerted by the often very compact natural structure of the plant especially in the case of woody plants such as myrtle to facilitate the solvent diffusion.

\section{Quantification of total flavonoid and total phenol contents}

\section{Spectrophotometry quantification of total flavonoids (TF)}

For total flavonoids of myrtle leaves, the best processing conditions were obtained at a saturated steam pressure of $0.5 \mathrm{MPa}$, a treatment

\begin{tabular}{|l|l|l|l|}
\hline \multirow{2}{*}{\multicolumn{1}{c|}{$\begin{array}{c}\text { Myrtle leaf flavonol aglycone } \\
\text { compounds }\end{array}$}} & \multicolumn{2}{|c|}{ RM yields } & \multicolumn{2}{c|}{ DIC-M Yields } & \multirow{2}{*}{$\begin{array}{c}\text { Improvement ratio based } \\
\text { on RM (\%) }\end{array}$} \\
\cline { 2 - 3 } & \multicolumn{2}{|c|}{$(\mathrm{mgMyrE} / \mathrm{gdb})$} & $316 \%$ \\
\hline Compound 1: myricetin & 2.17 & 9.02 & $-24 \%$ \\
\hline Compound 2: myricetin 3-O-methyl & 10.71 & 8.11 & $+6200 \%$ \\
\hline Compound 3: unknown compound & 0.01 & 0.63 & $110 \%$ \\
\hline Compound 4: quecetin & 0.77 & 1.62 & $-40 \%$ \\
\hline Compound 5: kaempferol & 0.15 & 0.09 & $-0.15 \%$ \\
\hline Compound 6: unknown flavonol & 0.15 & 0.13 & \\
\hline
\end{tabular}

Table 4: Yields of the compounds of flavonol aglycones contained in the untextured and DIC textured (at $0.5 \mathrm{MPa}, 180 \mathrm{~s}$ and 5 cycles) myrtle leaves.

RM yields: Yields from untextured raw material; DIC-M yields: Yields from DIC-textured leaves. 
Citation: Berka B, Besombes C, Hassani A, Allaf K (2019) Thermomechanical Texturing by Instant Controlled Pressure-Drop DIC or How to Dramatically Intensify both Polyphenol Extraction and Antioxidant Activity of Algerian Myrtle leaves. Int J Clin Nutr Diet 5: 148. doi: https://oi.org/10.15344/2456-8171/2019/148

Page 10 of 15

time of $180 \mathrm{~s}$, and a number of cycles equal to 5 . They were identical to those obtained for flavonol aglycones quantified by HPLC. Yields were estimated from the calibration line obtained for different concentrations of $(+)$-catechin under the same test conditions as the extracts. They are expressed as milligrams of catechin equivalent per gram of dry basis (mgCatE/g db).

The best performance was rated at $26.01 \mathrm{mgCatE} / \mathrm{g} \mathrm{db}$ for DIC textured myrtle leaves. Regarding the untextured raw material, the extracted amount was $10.40 \mathrm{mgCatE} / \mathrm{g} \mathrm{db}$. Optimized DIC treatment achieved an improvement of flavonoid content of about 150\%.The results shown in Figure 8 demonstrated that the higher the steam pressure, the higher the yields. The impact of total heating time of DIC was very weak whereas the impact of the number of cycles was the most influential factor.

\section{Spectrophotometry quantification of total phenols (TP)}

Yields were estimated from the calibration line obtained for different concentrations of gallic acid under the same test conditions as the extracts. They are expressed in milligrams of gallic acid equivalent per gram of dry basis (mgGAE/g db).

For total phenols best performance was not obtained at the same DIC conditions of $0.5 \mathrm{MPa}, 180 \mathrm{~s}$ and 5 cycles but at $0.35 \mathrm{MPa}, 120 \mathrm{~s}$ and 6 cycles. In the case of total flavonoids myrtle spectrophotometrically determined, the number of cycles had more significant effect on the yield than the pressure and total heating time. This effect was more pronounced in the case of total phenols embodied here by a greater influence of number of cycles (six). The maximum total phenol yield of the textured leaves was 229.75 against $101.37 \mathrm{mgGAE} / \mathrm{g} \mathrm{db}$ for the untextured raw material. This increase was evidenced by a great improvement ratio of $126.64 \%$ compared to the untextured material whose performance kept the lowest. The number of cycles had more impact than pressure on the total phenol yield. Total heating time impact was insignificant (Figure 8). This optimum performance was close to that obtained in the processing conditions of $0.50 \mathrm{MPa}$, $180 \mathrm{sec}$ and 5 cycles; this second-best performance was evaluated at $217.22 \mathrm{mgGAE} / \mathrm{g} \mathrm{db}$.
The resulting values of these analyzes show a significant correlation between total flavonoids (TF) and total phenols (PT). The strength of this correlation is evaluated by the R2 around $90 \%$ (Figure 9). The error made by the model does not exceed $10 \%$.

\section{Scanning electron microscopy: photomicrograph untextured and DIC textured myrtle leaves}

In vascular plants cellulose is a major constituent of plant, particularly in cell walls. Methylated flavonoidsas flavonoidderivatives are often accumulated in exudates at the leaf surface. The flavonols are generally localized in the outer cell layers which constitute the epidermis.

For DIC textured leaves, the rich-in-hole surface is almost cellulose-empty. Although the cross-section indicates a change of the overall structure, the processing impact is much more pronounced at the surface. This change in structure caused by DIC treatment jointly facilitated the accessibility to the target compounds and their availability and aptitudes versus the extraction operation became much higher. This phenomenon was probably facilitated by a decrease of the cellulose, which usually reduces aglycone flavonol extraction. Solvent transfer from the outside to the inside of the plant and vice versa is then easier. Consequently, this allows obtaining an intensification of the extraction kinetics and a significant reduction in extraction time.

The microstructures were observed through environmental JEOL 5410LV FEI Quanta 200F kind, Philips, Scanning Electronic Microscope (SEM) (Croissy-sur-Seine, France). They highlight the structural variations of the myrtle leaves at surface (Figure 10a and b) and in volume (Figure $10 \mathrm{c}$ and d), for untreated material and after DIC treatment, respectively.

\section{Free radical-scavenging assay on DPPH}

The total reduction of DPPH • radical by antioxidant molecules in the flavonic extract was escorted by a complete discoloration

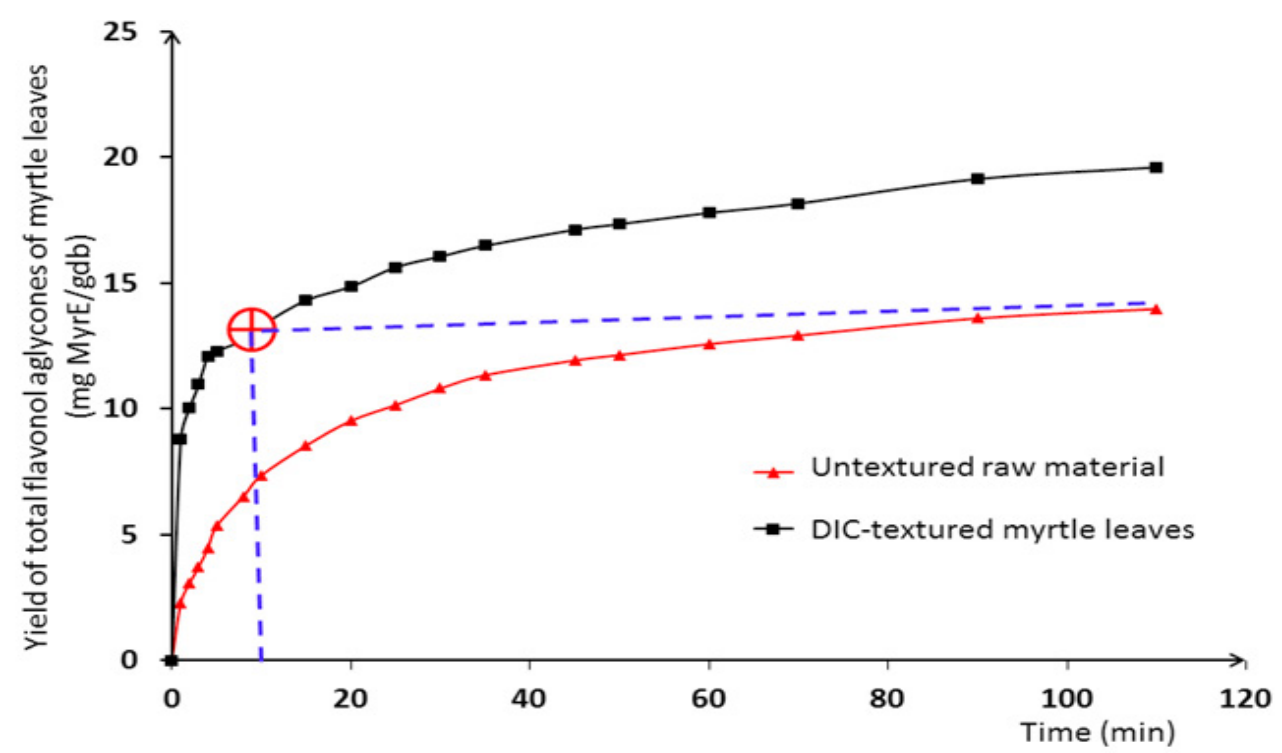

Figure 7: Curve of extraction of total flavonol aglycones TFA from myrtle leaves for untextured and DIC textured materials. 
Citation: Berka B, Besombes C, Hassani A, Allaf K (2019) Thermomechanical Texturing by Instant Controlled Pressure-Drop DIC or How to Dramatically Intensify both Polyphenol Extraction and Antioxidant Activity of Algerian Myrtle leaves. Int J Clin Nutr Diet 5: 148. doi: https://oi.org/10.15344/2456-8171/2019/148

(a)

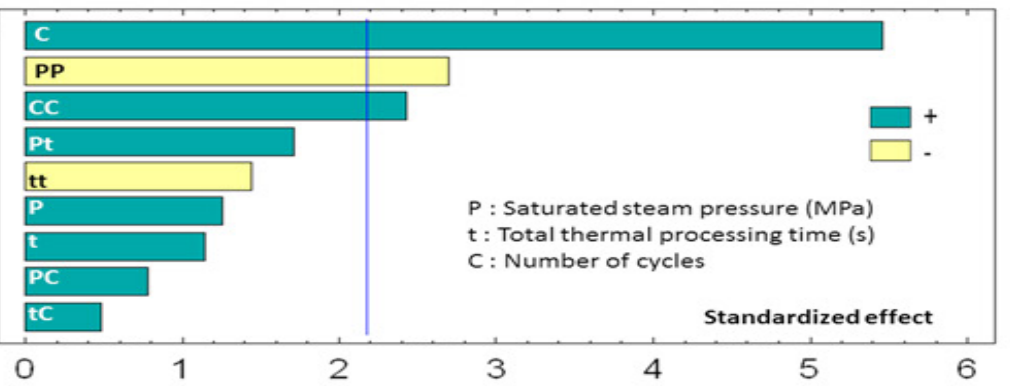

(b)

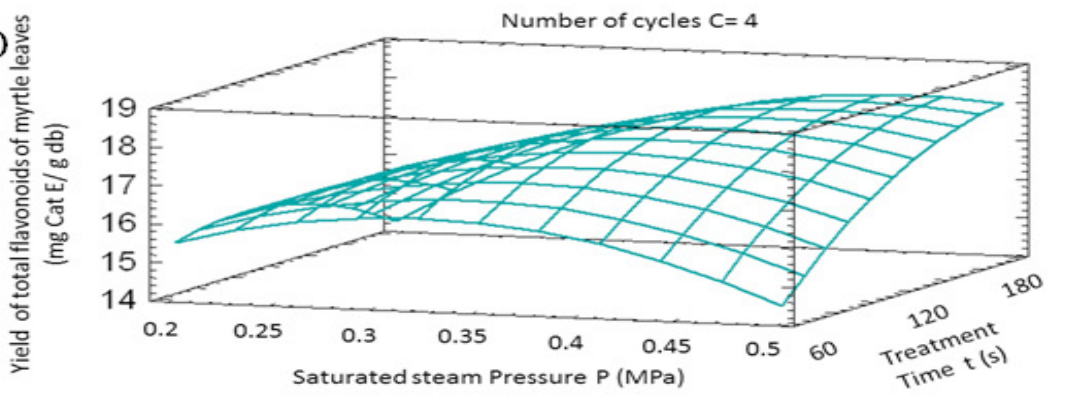

(c)
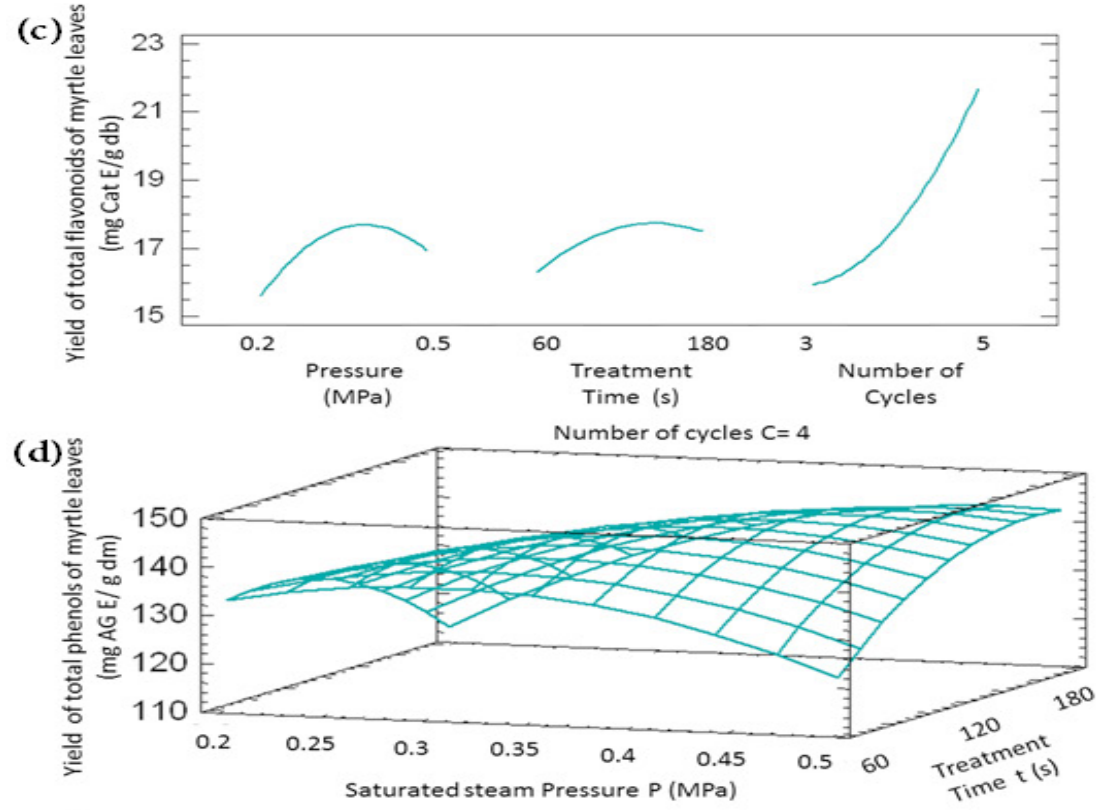

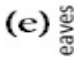

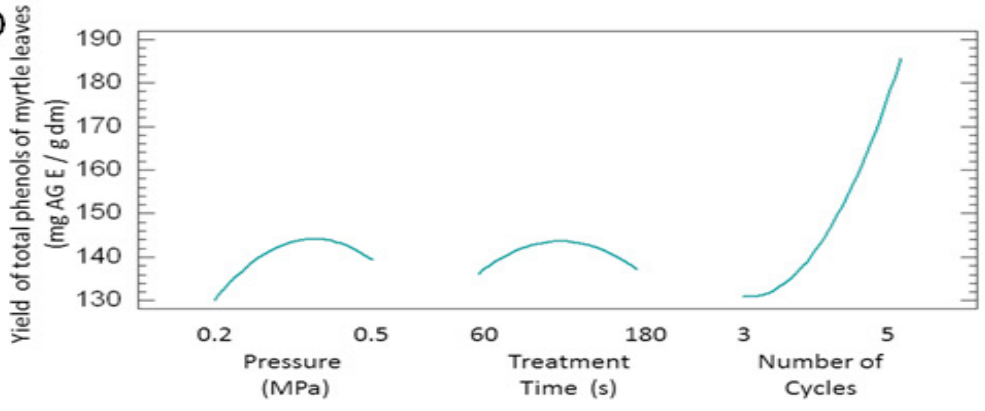

Figure 8: Effects of DIC treatment on the yields of total flavonoids: a) Pareto chart at confidence of $95 \%$ forp-value $<0.05$ ); b) Response surface depending on steam pressure and treatment time at number of cycles 4 , and c) general trends; and d) total phenolsResponse surface depending on steam pressure and treatment time at number of cycles 4 , and e) general trends; extracted from the textured myrtle leaves (obtained by spectrophotometry). 
Citation: Berka B, Besombes C, Hassani A, Allaf K (2019) Thermomechanical Texturing by Instant Controlled Pressure-Drop DIC or How to Dramatically Intensify both Polyphenol Extraction and Antioxidant Activity of Algerian Myrtle leaves. Int J Clin Nutr Diet 5: 148. doi: https://doi.org/10.15344/2456-8171/2019/148

Page 12 of 15

\begin{tabular}{|l|l|l|l|l|l|l|l|}
\hline Trial $^{\circ}$ & $\mathrm{P}(\mathrm{MPa})$ & $\mathrm{t}(\mathrm{s})$ & $\mathrm{C}$ & $\mathrm{TF}(\mathrm{mg}$ CatE/g db) & TP $(\mathrm{mg}$ GAE/g db) & TF $(\%)$ & TP $(\%)$ \\
\hline Raw material (RM) & & & & $10.40 \pm 0.37$ & $101.37 \pm 0.54$ & $100 \%$ & $100 \%$ \\
\hline CP 8 (DIC-CP) & 0.35 & 120 & 4 & $17.65 \pm 0.49$ & $143.77 \pm 3.05$ & $170 \% \pm 5 \%$ & $142 \% \pm 3 \%$ \\
\hline DIC1 & 0.2 & 180 & 5 & 17.28 & 126.42 & $166 \%$ & $125 \%$ \\
\hline DIC2 & 0.1 & 120 & 4 & 14.44 & 128.59 & $139 \%$ & $127 \%$ \\
\hline DIC3 & 0.35 & 19 & 4 & 14.76 & 128.42 & $142 \%$ & $127 \%$ \\
\hline DIC5 & 0.5 & 60 & 5 & 19.10 & 180.40 & $184 \%$ & $178 \%$ \\
\hline DIC7 & 0.2 & 180 & 3 & 13.82 & 124.42 & $133 \%$ & $123 \%$ \\
\hline DIC8 & 0.5 & 180 & 3 & 16.92 & 127.59 & $163 \%$ & $126 \%$ \\
\hline DIC10 & 0.35 & 120 & 2 & 15.07 & 133.27 & $145 \%$ & $131 \%$ \\
\hline DIC12 & 0.2 & 60 & 5 & 18.57 & 160.47 & $179 \%$ & $158 \%$ \\
\hline DIC13 & 0.2 & 60 & 3 & 12.95 & 114.23 & $125 \%$ & $113 \%$ \\
\hline DIC14 & 0.35 & 120 & 6 & 25.03 & 229.75 & $241 \%$ & $227 \%$ \\
\hline DIC16 & 0.6 & 120 & 4 & 11.35 & 101.43 & $109 \%$ & $100 \%$ \\
\hline DIC19 & 0.5 & 180 & 5 & 26.01 & 217.22 & $250 \%$ & $214 \%$ \\
\hline DIC20 & 0.35 & 221 & 4 & 14.53 & 112.73 & $140 \%$ & $11 \%$ \\
\hline DIC22 & 0.5 & 60 & 3 & 14.83 & 107.88 & $143 \%$ & $106 \%$ \\
\hline
\end{tabular}

Table 5: Quantification of total flavonoids (TF) and total phenols (TP).

DIC conditions P: saturated steam pressure, t: thermal treatment time, C: number of cycles; CP 8 (DIC-CP) Central Points.TF: Total flavonoids; TP: Total phenols; RM yields: Yields from untextured raw material; DIC-M yields: Yields from DIC-textured leaves.

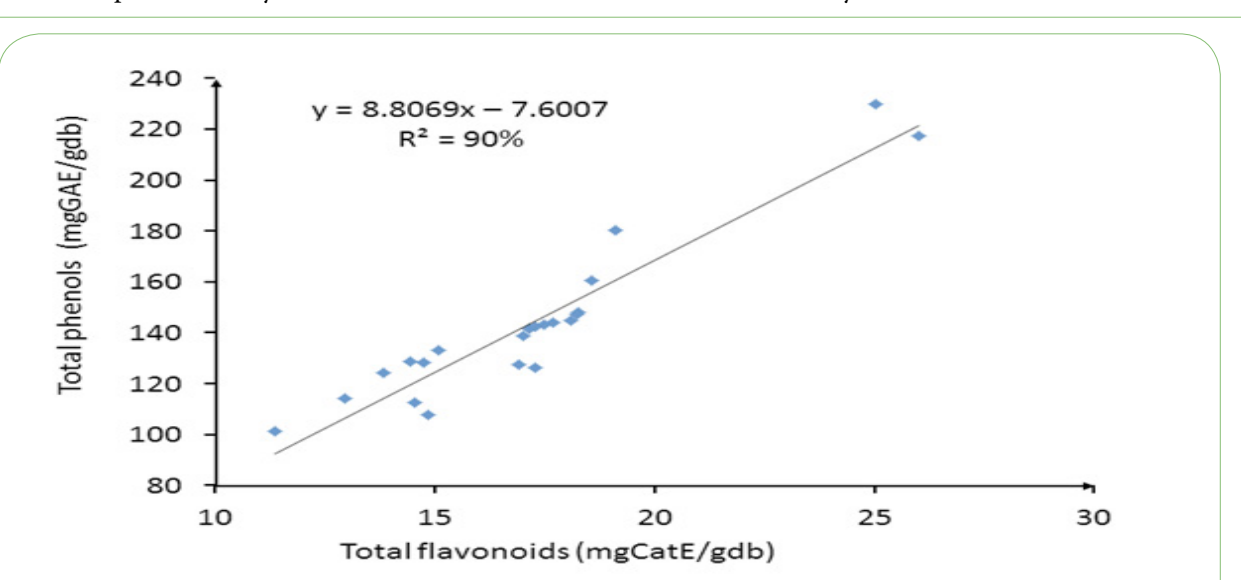

Figure 9: Correlation between yields of total flavonoids and total phenols obtained at various DIC texturing conditions.
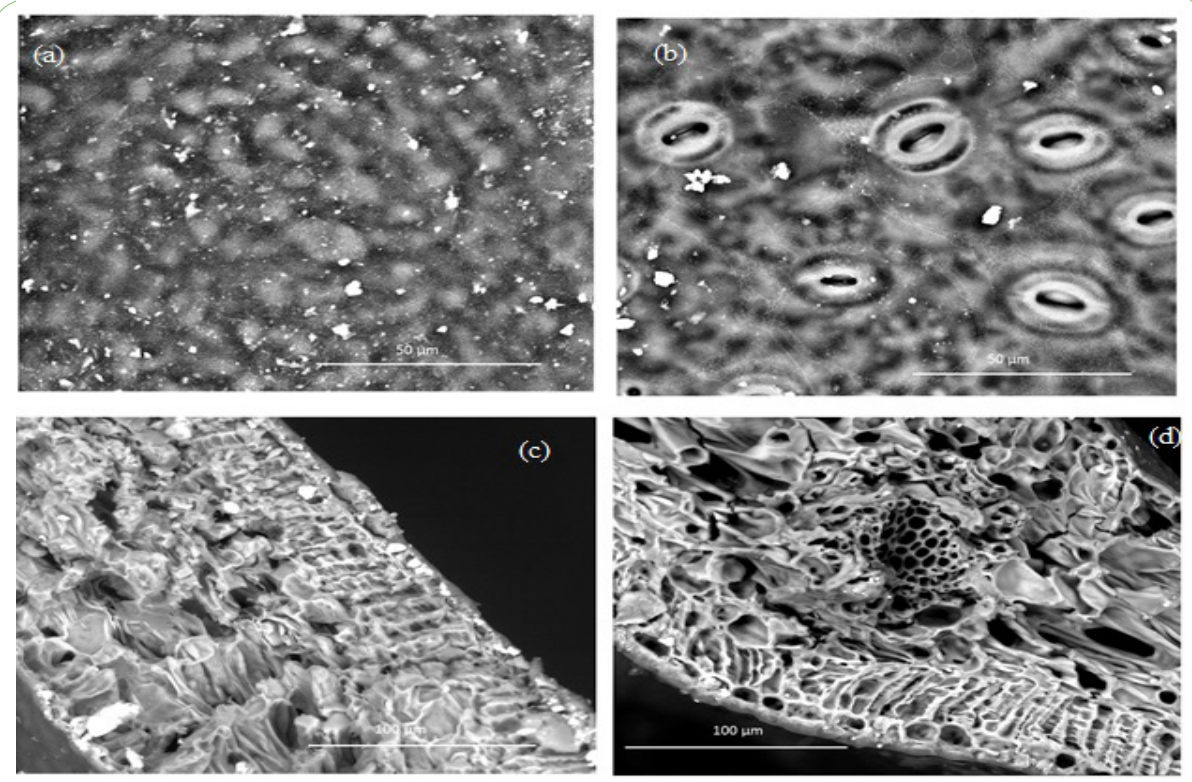

Figure 10: Impacts of DIC treatment on anatomic structure of myrtle leaves at surface ( $a$ and $b$ ) and in volume ( $\mathrm{c}$ and $\mathrm{d}$ ), for untreated and DIC treated materials, respectively. 
Citation: Berka B, Besombes C, Hassani A, Allaf K (2019) Thermomechanical Texturing by Instant Controlled Pressure-Drop DIC or How to Dramatically Intensify both Polyphenol Extraction and Antioxidant Activity of Algerian Myrtle leaves. Int J Clin Nutr Diet 5: 148. doi: https://doi.org/10.15344/2456-8171/2019/148

Page 13 of 15

to pale yellow. This is due to the formation of the stable molecule (2,2-diphenyl-1-picrylhydrazine (DPPHH). Although the reaction mechanism occurring between the DPPH $\bullet$ radical and the antioxidant strictly depends on structure [42], this reduction of $\mathrm{DPPH} \bullet$ radical is the result of two fundamentally different reaction mechanisms (32) and (43). These mechanisms are due to a hydrogen atom transfer (HAT) or an electron transfer (ET) from the antioxidant to DPPH. radical, which has an electron on one of the nitrogen atoms.

The first mechanism (hydrogen atom transfer (HAT)) is based on the ability of the antioxidant ArOH (phenolic compound) to give a hydrogen atom to DPPH• radical according to following reaction [1]

\section{$\mathrm{DPPH}+\mathrm{ArOH} \rightarrow \mathrm{DPPHH}+\mathrm{ArO} \cdot$}

(Reaction 1)

The phenolic hydrogen has a high mobility, which enables it to effectively react with the free radical DPPH following this reaction (1).

The second mechanism (electron transfer (ET)) is itself based on the reducing capacity of the antioxidant $\mathrm{ArOH}$ (phenolic compound) to offer an electron (e-) to the DPPH' radical following reaction (2):

$$
\begin{array}{ll}
\mathrm{DPPH}+\mathrm{ArOH} \rightarrow \mathrm{DPPH}+\mathrm{ArOH}^{++} & \text {(Reaction 2) } \\
\mathrm{ArOH}{ }^{++}+\mathrm{H}_{2} \mathrm{O} \leftrightarrow \mathrm{ArO}+\mathrm{H}_{3} \mathrm{O}^{+} & \text {(Reaction 3) } \\
\mathrm{DPPH}+\mathrm{H}_{3} \mathrm{O}^{+} \leftrightarrow \mathrm{DPPHH}+\mathrm{H}_{2} \mathrm{O} & \text { (Reaction 4) }
\end{array}
$$

Wright et al. [43] explained the often very powerful reactivity of polyphenols against free radicals by their large ionization potential.
It reflects the ability and ease that have polyphenols to transfer an electron to the radical [2]. The rupture of the $\mathrm{O}-\mathrm{H}$ bond is heterolytically in second stage (3).

The percentage of residual or unreacted DPPH ${ }^{\bullet}$ radical is calculated based on the following formula:

$$
D P P H_{\text {residuel }}^{\bullet}(\%)=\frac{\left(A b s_{\text {temoin }}-A b s_{\text {echantillon }}\right)}{\left(A b s_{\text {temoin }}\right.}
$$

with;

$\mathrm{Abs}_{\text {control }}$ : absorbance of DPPH• without extract (measured against a blank of $2.5 \mathrm{ml}$ of solution with $1.5 \mathrm{ml}$ of methanol).

$\mathrm{Abs}_{\text {echantillon }}$ : absorbance of DPPH• with extract (measured against a blank).

The antioxidant activity was evaluated by the concentration required to inhibit or trap $50 \%$ of DPPH• radicals. This concentration is inversely proportional to the efficiency of the antioxidant activity. It is represented by $\mathrm{IC}_{50}$. This is determined by linear graph percentages of residual DPPH. radical (Equation 3) depending on the extract concentrations regression (antioxidant flavonoid extracts or reference). All measurements were triplicated. For each extract, the average

\begin{tabular}{|c|c|c|c|c|}
\hline DIC treatment conditions & $\mathrm{P}(\mathrm{MPa})$ & $t(s)$ & $\mathrm{C}$ & $\mathrm{IC}_{50}(\mu \mathrm{g} / \mathrm{ml})$ \\
\hline Reference: Gallic acid & 1 & 1 & 1 & $6.26 \pm 0.03$ \\
\hline Reference: Quercetin & 1 & 1 & 1 & $14.12 \pm 0.07$ \\
\hline Reference: BHT & l & 1 & 1 & $48.13 \pm 0.13$ \\
\hline Untreated myrtle (RM) & l & 1 & 1 & $2.18 \pm 0.07$ \\
\hline CP 8 (DIC-CP) & 0.35 & 120 & 4 & $1.52 \pm 0.05$ \\
\hline DIC1 & 0.20 & 180 & 5 & 1.31 \\
\hline DIC2 & 0.10 & 120 & 4 & 1.75 \\
\hline DIC3 & 0.35 & 19 & 4 & 1.37 \\
\hline DIC5 & 0.50 & 60 & 5 & 1.07 \\
\hline DIC7 & 0.20 & 180 & 3 & 2.14 \\
\hline DIC8 & 0.50 & 180 & 3 & 1.29 \\
\hline DIC10 & 0.35 & 120 & 2 & 1.64 \\
\hline DIC12 & 0.20 & 60 & 5 & 1.06 \\
\hline DIC13 & 0.20 & 60 & 3 & 2 \\
\hline DIC14 & 0.35 & 120 & 6 & 0.91 \\
\hline DIC16 & 0.60 & 120 & 4 & 1.77 \\
\hline DIC19 & 0.50 & 180 & 5 & 0.78 \\
\hline DIC20 & 0.35 & 221 & 4 & 1.96 \\
\hline DIC22 & 0.50 & 60 & 3 & 1.9 \\
\hline
\end{tabular}
values of each concentration were expressed as micrograms per ml of methanolic extract solution. The results of the antioxidant activities of the extracts and those taken as references are given in Table 6.

The results obtained in this study showed that the extracts obtained from untextured and DIC textured myrtle leaves presented a great reduction potential versus DPPH• radical.

Table 6: Minimum inhibitory concentrations trade IC50 $(\mu \mathrm{g} / \mathrm{ml})$ of untextured raw material (RM) and DIC-textured myrtle leaves (TM) and antioxidant references.

DIC conditions P: saturated steam pressure, t: thermal treatment time, C: number of cycles. IC50: Minimum inhibitory concentrations trade; CP 8 (DIC-CP) Central Points. 
Citation: Berka B, Besombes C, Hassani A, Allaf K (2019) Thermomechanical Texturing by Instant Controlled Pressure-Drop DIC or How to Dramatically Intensify both Polyphenol Extraction and Antioxidant Activity of Algerian Myrtle leaves. Int J Clin Nutr Diet 5: 148. doi: https://oi.org/10.15344/2456-8171/2019/148

Page 14 of 15

DIC treatment had an overall positive effect on the inhibitory activity of polyphenols vis-à-vis the radical DPPH•. Indeed, the extract of untextured myrtle leaves reduced by $50 \% \mathrm{DPPH}$ free radicals with a minimum concentration of $2.18 \mu \mathrm{g} / \mathrm{ml}$. For DIC textured myrtle, all points had higher antioxidant activity than the raw material. The values ranged between 2.14 and $0.78 \mu \mathrm{g} / \mathrm{ml}$. Furthermore, the optimal point of $\mathrm{IC}_{50}=0.78 \mu \mathrm{g} / \mathrm{ml}$ was obtained through the DIC treatment at $0.50 \mathrm{MPa}, 180 \mathrm{sec}$ and 5 cycles. This is the same point at which the best performance in total flavonol aglycone was obtained. The conditions that allowed having the greatest yield of total phenols $(0.35 \mathrm{MPa}, 120 \mathrm{~s}$ and 6 cycles) were also allowed to get a high antioxidant potential extract, with $\mathrm{IC}_{50}=0.91 \mu \mathrm{g} / \mathrm{ml}$. Consequently, DIC treatment generated interesting antioxidant activity performance, which was about 62 more effective than BHT and three times higher than that of the untreated raw material.

These results show a positive correlation between PT, and FT, on one hand, and the antioxidant activity, on the other hand with correlation factor $\mathrm{R}^{2}$ of $69 \%$ and $72 \%$, respectively (Figure 11 ).
Although phenolic content remains essential, other several factors may influence the reduction potential of an extract containing antioxidants, including antioxidant ratio $\mathrm{DPPH} \bullet$, the solvent nature, $\mathrm{pH}$, light, etc. [44-45]. In addition, the synergistic effects of different antioxidant compounds should not be neglected and can also cause an effective antioxidant activity.

\section{Conclusion}

From this study it follows that the extraction performance of flavonols may be modulated according to the texturing conditions of Instant controlled pressure drop DIC. DIC-assisted extraction can be considered as innovative operation of extraction of flavonoids and flavonoid aglycones. DIC also allows good control of both quantitative and qualitative level. It uniquely combines rapid extraction kinetics of flavonols with an efficient "starting accessibility".

DIC treatment conditions were optimized using a design of experiments. It allowed getting richer flavonoids extracts and more effective antioxidant activity in comparison with the untreated raw

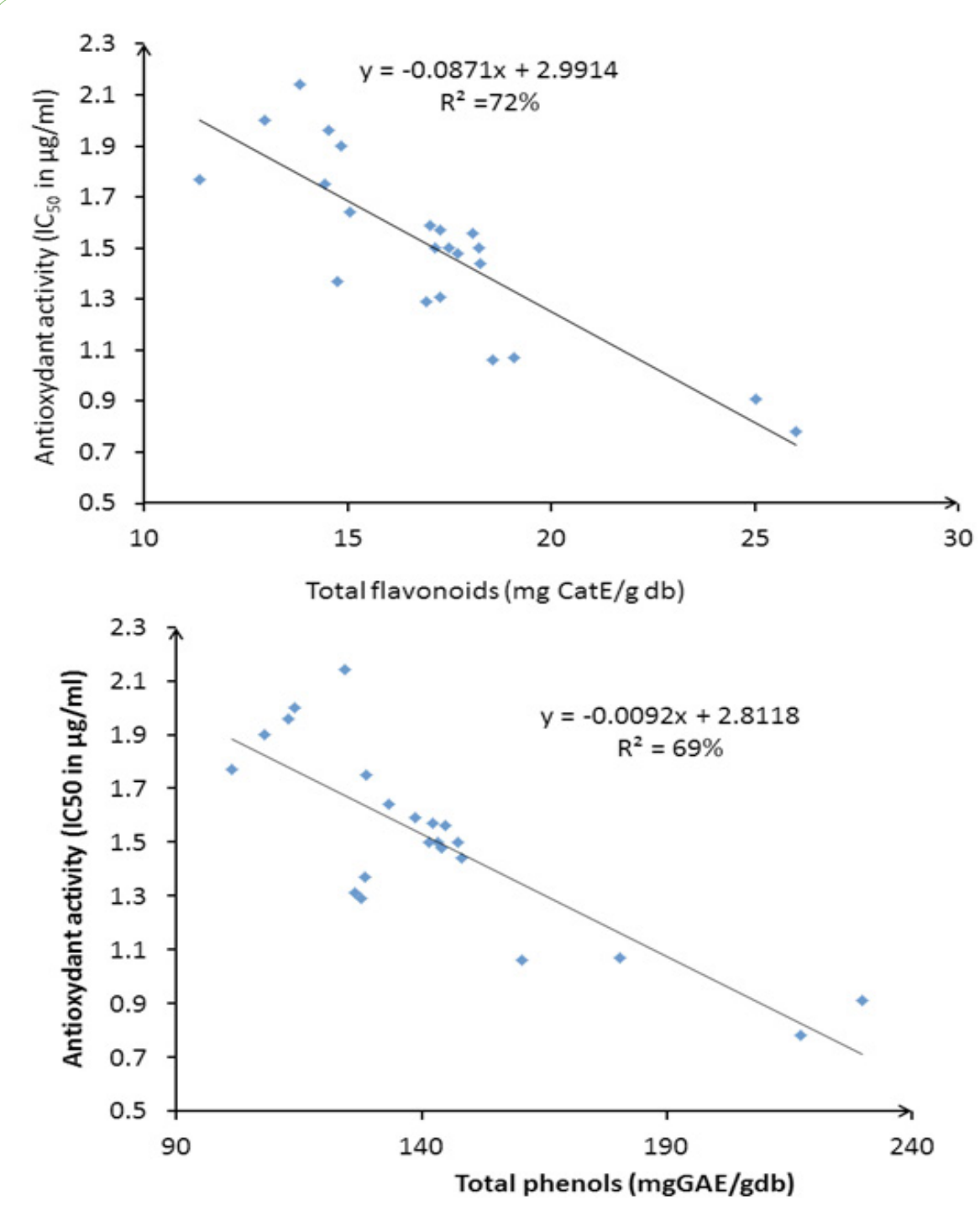

Figure 11: Correlations between Total Flavonoids TF and Total Phenols TP; and the antioxidant activity, with correlation factor $\mathrm{R}^{2}$ of $69 \%$ and $72 \%$, respectively. 
Citation: Berka B, Besombes C, Hassani A, Allaf K (2019) Thermomechanical Texturing by Instant Controlled Pressure-Drop DIC or How to Dramatically Intensify both Polyphenol Extraction and Antioxidant Activity of Algerian Myrtle leaves. Int J Clin Nutr Diet 5: 148. doi: https://oi.org/10.15344/2456-8171/2019/148

Page 15 of 15

material and conventional antioxidants such as BHT. The performance of antioxidant activity, greatly intensified after DIC treatment, was evaluated as 2.8 times and 62 times higher than that of untreated raw material and the synthesized antioxidant used as a reference namely BHT, respectively. It is worth noting that all these results suggest a better exploitation of myrtle as an industrially potential source of natural antioxidants. Consequently, myrtle can be used as additive to maintain the organoleptic qualities of rich-in-lipid foods or cosmetics in close contact with oxidizing agents such as oxygen. Performances of this innovative solvent extraction method impacts favorable economic and environmental benefits in addition to its general interest.

\section{Acknowledgements}

The authors would like to thank Mrs. Egle Conforto, specialist in materials and biomaterials analyses in La Rochelle University for her great work in correlating microstructural characteristics with physical and functional properties of plant-based materials. We, also, thank ABCAR-DIC PROCESS SAS (La Rochelle, France) for providing Labscale and pilot-scale DIC units.

\section{Competing Interests}

The authors declare that they have no competing interests.

\section{References}

1. Sumbul S, Ahmad MA, Asif M, Akhtar M (2011) Indian J Natural Products and Resources 2: 395-402.

2. Al-zohyri AM, Al-Jeboory AA, Abdul L, Jawad M (1985) Indian J Pharmaco 17: 233 .

3. Gündüz GT, Gönül SA, Karapinar M (2009) Int J Food Microbiol 130: 147 150.

4. Aydın C, Özcan MM (2007) J Food Eng 79: 453-458.

5. Sissi HIE, Ansary MAIE (1967) Planta Med 15: 41-51.

6. Barboni T, Cannac M, Massi L, Perez-Ramirez Y, Chiaramonti N, et al. (2010) Molecules 15: 7849-7860.

7. Gardeli C, Vassiliki P, Athanasios M, Kibouris T, Komaitis M, et al. (2008) Food Chem 107: 1120-1130.

8. Tuberoso CIG, Rosa A, Bifulco E, Melis MP, Atzeri A, et al. (2010) Food Chem 123: $1242-1251$.

9. Amensour M, Sendra E, Abrini J, Bouhdid S, Pérez-Alvarez JA, et al. (2009) Nat Prod Commun 4: 819-824.

10. Yoshimura M, Amakura Y, Tokuhara M, Yoshida T (2008) J Nat Med 62 366-368

11. Gilgun-Sherki Y, Melamed E, Offen D (2001) Neuropharmacology 40: 959975

12. Asres K, Seyoum A, Veeresham C, Bucar F, Gibbons S, et al. (2005) N Phytother Res 19: 557-581.

13. Gonçalves JLS, Leitão SG, Monache FD, Miranda MMFS, Santos MGM, et al. (2001) Phytomedicine 8: 477-480.

14. Gurib-Fakim A (2006) Mol Aspects Med 27: 1-93.

15. Kahl R, Kappus HZ (1993) Lebensm Unters Forsch 196: 329-338.

16. Valentão P, Fernandes E, Carvalho F, Andrade PB, Seabra RM, et al. (2002) J Agric Food Chem 50: 4989-4993.

17. Sokół-Łętowska A, Oszmiański J, Wojdyło A (2007) Food Chem 103: 853859

18. Ortega RM (2006) Public Health Nutr 9: 1136-1140

19. Li K, Landriault M, Fingas M, Llompart M (1998) Analysis 26: 365-369.

20. Kaufmann B, Christen P (2002) Phytochem Anal 13: 105-113.

21. Wang J, Sun B, Cao Y, Tian Y, Li X (2008) Food Chem 106: 804-810.
22. Zill-e-Huma, Abert-Vian M, Elmaataoui M, Chemat F (2011) J Food Eng 105 351-360.

23. Huang W, Xue A, Niu H, Jia Z, Wang J (2009) Food Chem 1140: 1147-1154.

24. Wang L, Weller CL (2006) Trends Food Sci Technol 17: 300-312.

25. Allaf T, Besombes C, Tomao V, Chemat F, Allaf K, et al. (2014) In: Allaf T, Allaf $\mathrm{K}$, editors. Springer New York.

26. Albitar N, Mounir S, Besombes C, Allaf K (2011) Dry Technol 29: 993-1001.

27. Rochová K, Sovová H, Sobolík V, Allaf K (2008) J Supercrit Fluids 44: 211 218.

28. Berka-Zougali B, Besombes C, Allaf T, Allaf K (2014) In: Allaf T, Allaf K, editors. Springer New York.

29. Ben Amor B, Allaf K (2009) Food Chem 115: 820-825.

30. Berka-Zougali B, Hassani A, Besombes C, Allaf K (2010) J Chromatogr A 1217: 6134-6142.

31. Zhishen J, Mengcheng T, Jianming W (1999) Food Chem 64: 555-559.

32. Huang D, Ou B, Prior RL (2005) J Agric Food Chem 53: 1841-1856.

33. Berka B, Hassani A, Allaf K, Weaver G (2015) Cogent Chem 1: 1087109.

34. Martín T, Rubio B, Villaescusa L, Fernández L, Díaz AM (1999) Pharm Biol 37: 28-31.

35. Romani A, Coinu R, Carta S, Pinelli P, Galardi C, et al. (2004) Free Radic Res 38: 97-103.

36. Romani A, Pinelli P, Mulinacci N, Vincieri FF, Tattini M, et al. (1999) Chromatographia 49: 17-20.

37. Barboni T, Venturini N, Paolini J, Desjobert JM, Chiaramonti N, et al. (2010) Food Chem 122: 1304-1312.

38. Barboni T, Cannac M, Massi L, Perez-Ramirez Y (2010) Chiaramonti N Molecules 15: 7849-7860.

39. Nassar MI Aboutabl ESA, Ahmed RF, El-Khrisy EDA, Ibrahim KM, et al. (2010) Pharmacogn Res 2: 325-329.

40. Knekt $P$, Kumpulainen J, Järvinen $R$, Rissanen $H$, Heliövaara $M$, Reunanen $A$ et al. (2002) Am J Clin Nutr 76: 560-568.

41. Boots AW, Haenen GRMM, Bast A (2008) Eur J Pharmacol 585: 325-337.

42. Bondet V, Brand-Williams W, Berset C (1997) LWT - Food Sci Technol 30: 609-615.

43. Wright JS, Johnson ER, DiLabio GA (2001) J Am Chem Soc 123: 1173-1183.

44. Ozcelik B, Lee JH, Min DB (2003) J Food Sci 68: 487-490.

45. Sharma OP, Bhat TK (2009) Food Chem 113: 1202-1205.

\section{This article was originally published in a special issue}

Functional Foods and Nutraceuticals: Their Role in Disease Prevention

Handled by Editors:

Prof. Luciana Mosca (Lead Specail Issue Editor)

Department of Biochemical Sciences

University of Rome "La Sapienza"

Italy

Dr. Ilaria Peluso

Food and Nutrition Center

Agricultural Research Council (CRA-NUT)

Italy

Dr. Alessia Baseggio Conrado

Photobiology Unit at the Cancer Division

University of Dundee

United Kingdom

Dr. Anna Scotto D'abusco

Department of Biochemical Sciences

Sapienza University of Rome

Italy 